\title{
$L$-arginine as a novel target for clinical intervention in inflammatory bowel disease
}

\author{
Björn Nüse ${ }^{1}$, Jochen Mattner $^{1,2 *}$ \\ ${ }^{1}$ Mikrobiologisches Institut-Klinische Mikrobiologie, Immunologie und Hygiene, Universitätsklinikum Erlangen, Friedrich- \\ Alexander Universität (FAU) Erlangen-Nürnberg, 91054 Erlangen, Germany \\ ${ }^{2}$ Medical Immunology Campus Erlangen, FAU Erlangen-Nürnberg, 91054 Erlangen, Germany
}

*Correspondence: Jochen Mattner, Mikrobiologisches Institut-Klinische Mikrobiologie, Immunologie und Hygiene, Universitätsklinikum Erlangen, Friedrich-Alexander Universität (FAU) Erlangen-Nürnberg, Wasserturmstr. 3/5, 91054 Erlangen, Germany. Jochen.Mattner@uk-erlangen.de

Academic Editor: Xiaofeng Yang, Temple University School of Medicine, United States

Received: March 30, 2021 Accepted: Jun 8, 2021 Published: June 30, 2021

Cite this article: Nüse B, Mattner J. $L$-arginine as a novel target for clinical intervention in inflammatory bowel disease. Explor Immunol. 2021;1:80-9. https://doi.org/10.37349/ei.2021.00008

\begin{abstract}
Arginase-1 (Arg1) and the inducible nitric oxide synthase 2 (NOS2) compete for the common substrate $L$-arginine, semi-essential amino acid, and central intestinal metabolite. Both enzymes exhibit various, sometimes opposing effects on immune responses, tissue regeneration, or microbial growth and replication. In sub-mucosal tissues of patients suffering from inflammatory bowel disease (IBD), similar as in experimental colitis, the expression and activity of both enzymes, Arg1 and NOS2 are more prominent than in respective controls. Accordingly, the metabolism of $L$-arginine is altered in IBD patients. Thus, $L$-arginine represents a promising medical target for clinical intervention in these devastating diseases. Previous studies primarily focused on the host side of $L$-arginine metabolism. Initial reports using Arg1 inhibitors generated conflicting results in murine colitis models. Subsequently, only the generation of conditional Arg1 knockout mice allowed reliable functional analyses of Arg1 and the $L$-arginine metabolism in the immune system. Utilizing cell-specific conditional Arg1 knockouts, we have recently reported that Arg1, surprisingly, hampered the resolution of experimental colitis due to the restriction of the intraluminal availability of $L$-arginine. Reduced levels of $L$-arginine restrained the compositional diversity of the intestinal microbiota and subsequently the mutual metabolism between the microbiota and the host. Thus, the intraluminal microbiota represents a potential therapeutic target for $L$-arginine metabolism aside from host-dependent $L$-arginine consumption.
\end{abstract}

\section{Keywords}

Arginase-1, $L$-arginine, inflammatory bowel disease, colitis, gut microbiota, intestinal metabolism

\section{Introduction}

Inflammatory bowel disease (IBD) is a chronic, relapsing disorder of the gastrointestinal (GI) tract. IBD has been considered to be a problem of industrial-urbanized societies. However, the incidence and prevalence 
of IBD in developing countries are also steadily rising, presumably due to the rapid modernization and westernization of the population. Furthermore, patients acquire IBD nowadays in their younger and younger years and exhibit an increased risk of developing colorectal cancer (CRC) [1, 2]. Thus, IBD is an emerging threat to global health systems nowadays.

Patients suffering from IBD experience a severely reduced quality of life. Collectively, IBD can result in debilitating physical and psychosocial symptoms for patients and affect society through loss of schooling, absenteeism, and healthcare costs [3].

Current therapeutic options, which primarily aim to restrain intestinal inflammation, include nonsteroidal anti-inflammatory drugs (NSAIDs) as the first-line therapeutics, followed by steroids, and finally biological therapies in a step-by-step therapy regimen [4]. These therapeutic options are accompanied by several, sometimes serious, but frequently reversible side effects (e.g., headache, drug fever, skin fever, etc.) [5]. Importantly, biologic agents targeting genetic, geographic, or microbial factors induce remission in just $40 \%$ of all patients after 12 weeks [6]. Thus, new therapeutic targets and approaches are urgently required, as the incidence of IBD is dramatically rising $[7,8]$.

To date, IBD is known for over 220 years [9]. The term IBD was coined by Samuel Wilks 160 years ago [10]. It includes Crohn's disease (CD), ulcerative colitis (UC), and indeterminate colitis [11, 12]. IBD represents nowadays the most common disorder of the GI tract. It is characterized by an immune-mediated inflammation and/or ulceration of the gut $[12,13]$, that causes abdominal pain, (bloody) diarrhea, and/ or weight loss [14]. Both disorders usually affect predominantly the colon with mucosal lesions starting predominantly in the last section of the rectum. From there mucosal lesions can either spread continuously (UC) or in sections (CD) [15-18]. However, IBD patients do not only suffer from intestinal symptoms. Extraintestinal complications of IBD include anemia, arthritis, or primary sclerosing cholangitis (PSC) [19].

IBD are complex diseases, which arise as a consequence of dysregulated mutual interactions of the commensal microbiota with the humoral, the intestinal epithelial, and the cellular immune network of the gut in genetically susceptible individuals [20]. However, molecules, metabolites, and signaling pathways controlling the interactions of the intestinal microflora with the immune system of the patient and their role in the suppression of intestinal inflammation have been rarely identified.

\section{Genetic susceptibility in IBD}

Since concordance rates of $30 \%$ for CD and $15.4 \%$ for UC have been reported in monozygotic twins, the genetic component of IBD got in the focus of IBD research [21,22]. Genome-wide association studies (GWAS), frequently using chip assays for the detection of single nucleotide polymorphisms (SNPs), have identified more than 240 different susceptibility genes and potential risk loci for IBD to date [23-25]. For example, genetic polymorphisms of nucleotide-binding oligomerization domain 2 (Nod2), encoding for an intracellular pattern recognition receptor or of the interleukin (IL)-17/IL-23 cytokine axis exhibit the largest effect size in IBD $[22,25]$. Since the majority of these susceptibility genes encodes for molecules involved in the recognition of bacteria or pathways regulating the immune response to bacteria, gut-resident bacteria became another focus of interest [26].

\section{The role of $L$-arginine in IBD}

By exploring distinct pathways in IBD patients, which have gotten into remission, the branched-chain amino acid $L$-arginine and arginase-1 (Arg1), one of the enzymes using $L$-arginine as substrate, have been identified as promising targets [27]. Arg1 exerts pleiotropic immunoregulatory effects. Importantly, in contrast to the general idea of acting as an anti-resolvin [28], our recent publication suggests, that Arg1 impedes the resolution of colitis by altering the microbiome and metabolome due to the consumption of intraluminal $L$-arginine [29]. Since $L$-arginine metabolism is a pivotal factor for the resolution of colitis, several studies linked the complex $L$-arginine signaling network to genetic polymorphisms. Although there were no associations between Arg1 and Nod2 or between Arg1 and IL-17/IL-23 [30], intracellular pathogens are well known to induce Arg1 in mouse macrophages upon engagement of Toll-like receptors (TLRs) and 
signal transmission through the signal transducers and activators of transcription (STATs) [31], important genetic loci in IBD [31,32]. In addition, genetic polymorphisms in nitric oxide synthase 2 (NOS2) encoding for the inducible NOS2 are an increased risk factor specific for $\mathrm{CD}$, and polymorphisms in the gene encoding nuclear transcription factor-kappa B (NF-kB), a pleiotropic transcription factor, are linked to inflammatory Arg1 or NOS2 pathways [32-34].

\section{$L$-arginine converting enzymes in the pathogenesis of IBD}

$L$-arginine is a central intestinal metabolite [35], which is involved in numerous biologic processes during health or disease, including immune-mediated inflammation of the GI tract. Aside from being a precursor for nitric oxide (NO) and a regulator of nitrogen balance in the whole body, $L$-arginine is pivotal for the modification of proteins and the synthesis of polyamines [36, 37]. $L$-arginine is converted either by NOS2 into NO and citrulline or by Arg1 into ornithine and urea [29, 38, 39]. Thus, both iso-enzymes, Arg1 and NOS2 compete for the common substrate $L$-arginine [40]. While NO is known for potent anti-microbial and immune-regulatory activities, stimulating mucosal blood flow and mucus generation [38], Arg1 serves as a precursor for the synthesis of proline and polyamines which are involved in the proliferation of cells and collagen synthesis [41, 42] (Figure 1). In addition, Arg1 has been also linked to immune cell (dys-)function, resulting in an inhibition of $\mathrm{T}$ cell proliferation and subsequent immune suppression, causing increased availability of polyamines and impaired NO production [43]. Today their role in the pathogenesis of IBD is discussed controversially, letting $L$-arginine and Arg1 appear as Janus-like characters.

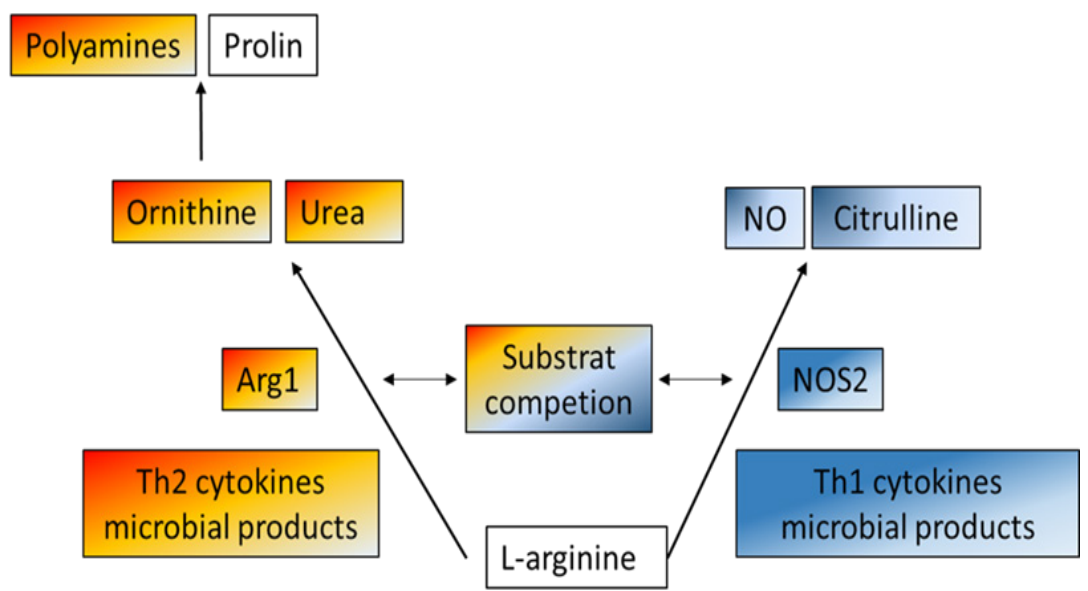

Figure 1. Metabolism of $L$-arginine-schematic and simplified overview of two main enzymatic pathways: Arg1 and NOS2 compete both for the common substrate $L$-arginine. While NOS2 converts $L$-arginine into citrulline and NO, known for potent antimicrobial and immunoregulatory activities, Arg1 metabolizes this semi-essential amino acid into proline and polyamines, which drive cell proliferation and collagen synthesis, but also in immune cell dys-function

On the one hand, Arg1 expression correlates with the degree of inflammation observed in tissue biopsies of patients suffering from IBD and in animal colitis models [29, 44-47]. Subsequently, the intraluminal availability of $L$-arginine is reduced in IBD patients [48]. Accordingly, improved intraluminal availability of $L$-arginine and genetic deletion of Arg1 in hematopoietic and endothelial cells mediated significant protection from experimental colitis [29].

On the other hand, the usage of arginase inhibitors led to conflicting results. For example, the blockade of Arg1 due to the oral application of $S$-(2-boronoethyl)-L-cysteine [49] or 2(S)-amino-6-boronohexanoic acid $\mathrm{NH}_{4}$ did not affect acute ongoing colitis [50]. Anti-colitogenic effects of chemical Arg1 blockade have been also reported [47]. Other studies describing the protective role of Arg1 in colitis, primarily used ex-vivo models. In these experiments, arginase activity was determined by cultivating protein [51] or macrophage supernatants [52] in Hank's balanced salt solutions (HBSS) containing $L$-arginine and ${ }^{14} \mathrm{C}$-arginine with or without the addition of nor-NOHA. For example, an increased Arg1 expression in the macrophages was expected due to indirect measurements of urea levels, a product of Arg1 metabolism [53]. Unfortunately, however, the transfer of the in vitro observations to direct in vivo models is missing in these studies, or in vivo models were not performed, presumably due to the limited availability of arginase inhibitors [52]. 
However, these data have to be interpreted with caution, as experiments were exclusively performed with arginase inhibitors. These can act unspecific, and their pharmacokinetic action and tissue distribution are not well understood. Furthermore, Arg1 inhibitors just achieve around 40\% inhibition of total Arg1 activity [50].

\section{M2 macrophages protect against intestinal inflammation}

During intestinal inflammation, macrophages might not control the replication, the growth, and/or the spread of microbes and thus can promote inappropriate inflammatory immune responses in mucosal tissues [54]. On the other hand, M2 macrophages expressing Arg1 as one cell-characteristic feature [55] have been associated with anti-colitogenic effects. M2 macrophages, activated by IL-4, perpetuate protection from experimental colitis through a reduction of inflammatory cytokine production in response to pro-inflammatory stimuli and an increased release of anti-inflammatory cytokines like IL-10 [56]. Protection can be mediated through the catalytic subunit activity of the class I phosphatidylinositol 3 kinase P110 $\delta$ of M2 macrophages [50].

Several reports suggested that the blockade of Arg1 activity by specific inhibitors resulted in a reduction of Arg $1^{+}$macrophages and an upregulation of NO expression [50,57]. However, it remained unclear whether the blockade of Arg1 was linked to a loss of M2 macrophage polarization. The effect of Arg1 depletion on other cell populations has not yet been explored; publications so far have only focused on macrophages or $\mathrm{F} 4 / 80^{+}$cell populations. Thus, it is still unknown, whether protection from colitis through M2 macrophages might be even independent of Arg1. Indeed the heterogeneous experimental outcomes suggest signals from the microenvironment rather than arginase inhibition of the host [50,58]. Surprisingly, microbiota, wellknown complex ecosystems that are structurally and functionally altered during colitis, were not investigated in these studies although most of the identified genetic risk loci in IBD were associated with microorganisms or host-microbiota interactions [26]. Thus, futures studies need to take into consideration the whole microenvironment, by determining the effects of Arg1 during colitis development and progression.

\section{Microbiota in IBD}

Gut microbiota is similar to the host a source of different metabolites including polyamines [59]. Bacteria like Firmicutes or Bacteroidetes associated with human health and/or the presence of anti-inflammatory microorganisms such as Bifidobacterium or Faecalibacterium are decreased in fecal samples of IBD patients [27, 60, 61]. At the same time Enterobacteriaceae, including Escherichia coli [62], and Helicobacter spp. are increased, which are known to contribute to the destruction of the colonic mucus layer [29, 60]. We also observed that the ratio of Firmicutes to Bacteroidetes is higher in Tie2-Cre $\times \operatorname{Arg} 1^{f / f l}$ mice lacking Arg1 in hematopoietic and endothelial cells compared to wild-type littermate controls $\left(\operatorname{Arg} 1^{f / f f}\right)$. In addition, bacterial genera are associated with human health as well as maintaining gut homeostases, like Ruminocococcus, Turicibacter, Fodinicurvata, Christensensella, Acetanaerobacteria, and Clostridia spp. show significant expansion in the Tie2-Cre $\times \operatorname{Arg} 1^{f / / f l}$ mice $[29,63,64]$.

\section{Reduced intraluminal availability of $L$-arginine impedes the resolution of colitis}

In the last two decades, in vivo models including the global or conditional knockout of either Arg1 or NOS2 were created [29, 65-67]. However, most of the published literature about the role of Arg1 during colitis, focused on specific conditional knockout models in different cell subsets, because a global knockout of Arg1 is lethal [68].

In the in vivo knockout models, $L$-arginine exhibited a Janus-faced function, depending on which kind of iso-enzyme utilized it as substrate. Recently published data assumed that an increased Arg1 expression triggered by the intestinal microbiota and by the Thelper type 2 (Th2), cytokines IL-4 and IL-13, perpetuated intestinal damage [29]. Knockouts of $\mathrm{Arg} 1$ in either myeloid (Cx3cr1-Cre $\left.\times \operatorname{Arg} 1^{1 / f f}\right)$ or endothelial cells (Cdh5Cre $\left.\times \operatorname{Arg} 1^{f / f f}\right)$ alone were not sufficient to significantly impact the progression of colitis. In contrast, mice with a knockout of $\operatorname{Arg} 1$ in endothelial and hematopoletic cells (Tie2-Cre $\times \operatorname{Arg} 1^{f / f}$ ), resolved colitis faster compared 
to respective littermate controls. The additional deletion of $\operatorname{Arg} 2$ encoding the mitochondrial iso-enzyme and NOS2 even decreased further the severity of colitis, as reported before [29, 51]. Thus, we concluded that the enzymatic consumption of intraluminal $L$-arginine through NOS2, Arg1, or other $L$-arginine converting enzymes promotes colitis. Subsequently, the supplementation of $L$-arginine in dextran sodium sulfate (DSS)treated mice improved intestinal pathology [48], while dietary $L$-arginine restriction resulted in progressive weight loss, IL-17 production, and fatal wasting disease [29]. The compositional changes of the microbiota and their reduced diversity promoted the production of pro-inflammatory cytokines in DSS-treated wildtype mice (Figure 2), while in Arg1 knockouts the anti-inflammatory immune response combined with the accumulation of intraluminal polyamines accelerated mucosal healing [29].

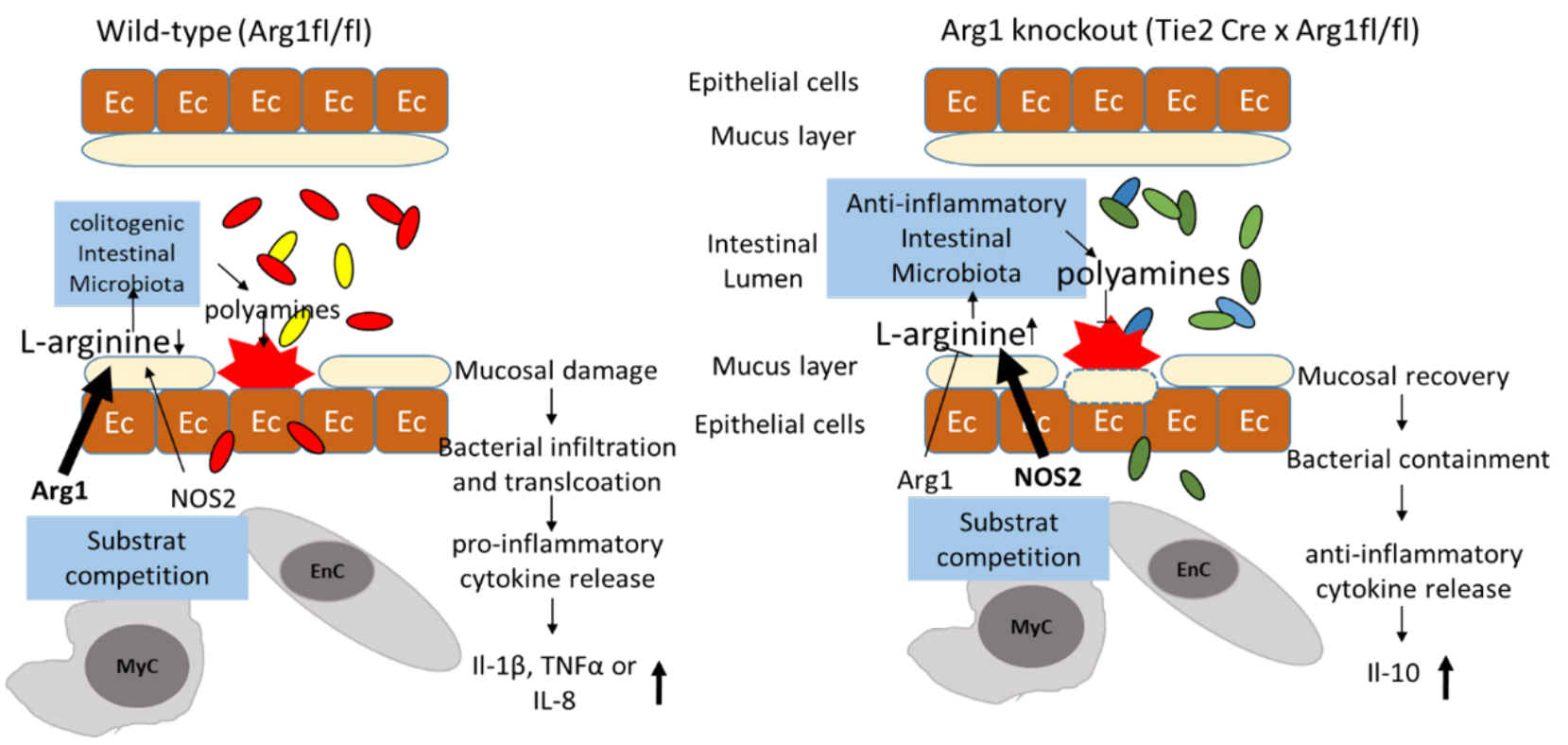

Figure 2. The availability of intraluminal $L$-arginine and subsequent changes in the composition of the intestinal microbiota: the availability of intraluminal $L$-arginine influences the bacterial diversity between wild-type mice (left panel) and mice with an Arg1 knockout in endothelial and hematopoietic cells (Tie2-Cre x Arg $1^{\text {tr/fil }}$; right panel). Once colitis is established, the increased expression of Arg1 in intestinal tissues accelerates the consumption of $L$-arginine, subsequently resulting in reduced diversity of intestinal microbiota. In contrast, intraluminal $L$-arginine is more available in Tie2-Cre $\times A r g 1^{f / f / l}$ mice, due to the lack of consumption by Arg1 in endothelial and myeloid. Commensal bacteria known for human health are increased in Tie2-Cre $\times$ Arg $1^{t / f / f}$ mice, metabolize $L$-arginine into polyamines and induce mucosal healing

Note. Adapted from "Arginase impedes the resolution of colitis by altering the microbiome and metabolome" by Baier J, Gänsbauer M, Giessler C, Arnold H, Muske M, Schleicher U, et al. J Clin Invest. 2020;130:5703-20 (https://www.jci.org/articles/view/126923). (c) 2020, American Society for Clinical Investigation.

The increased availability of intraluminal $L$-arginine is linked to a more physiologic and diverse microbiota. Interestingly, a fecal microbiota transfer from Arg1 knockout donors into wild-type recipients induced a significant reduction of intestinal damage and enhanced the recovery from colitis. Tie2-Cre $\times$ Arg $1^{f / / f l}$ mice show in comparison to wild-type controls also a different cytokine profile. Pro-inflammatory cytokines and cytokine receptors like IL-1 $\beta$, tumor necrosis factor (TNF), or IL-8 are reduced in Arg1 knockout mice and anti-inflammatory cytokines like IL-10 are enhanced [29].

According to the Janus-faced role of $L$-arginine during colitis, these studies suggest $L$-arginine as a promising new therapeutic approach in IBD and the metabolism of the microbiota as a pivotal target. To date clinical human trials and data from long-term studies are missing; however, they are urgently required to evaluate potential adverse effects and safety issues.

\section{Conclusion}

IBD affects patients life-long and severely affect their quality of life. Even though our knowledge about the pathogenesis of IBD has advanced in recent years, we are still just beginning to understand these devastating disorders. Therefore, we need to extend and improve current therapeutic options, which do not cure the underlying disease and force patients into remission by improving clinical symptoms at their best. Thus, novel targets and approaches for clinical intervention are urgently required. 
Recent publications suggest the metabolism of $L$-arginine, a central intestinal metabolite, and its metabolizing enzymes as promising novel avenues for treating IBD. Although the role of Arg1 and NOS2 during IBD is still controversial and results due to experimental limitations have to be interpreted and discussed with caution, one needs to consider that not only the host metabolizes $L$-arginine, but also its commensal microbiota, particularly in the gut. Thus, dietary supplementation of intraluminal $L$-arginine might act protective, due to the expansion of a local diverse microbiota. Furthermore, this locally restricted application of $L$-arginine might avoid the severe adverse effects observed following systemic infusion [69-71]. Thus, we need to further focus on the metabolism of the intestinal microbiota and the complex, mutual host-microbiota network in the future to establish $L$-arginine supplementation as a therapeutic option for IBD in the future $[29,48,72,73]$.

\section{Abbreviations}

Arg1: arginase-1

CD: Crohn's disease

GI: gastrointestinal

IBD: inflammatory bowel disease

IL: interleukin

NO: nitric oxide

NOS2: nitric oxide synthase 2

UC: ulcerative colitis

\section{Declarations}

\section{Author contributions}

BN wrote the first draft of the manuscript, selected the references, and designed the figures; JM wrote the manuscript. Both authors contributed to manuscript revision, read and approved the submitted version.

\section{Conflicts of interest}

The authors declare that they have no conflicts of interest.

\section{Ethical approval}

Not applicable.

\section{Consent to participate}

Not applicable.

\section{Consent to publication}

Not applicable.

\section{Availability of data and materials}

Not applicable.

\section{Funding}

This study was supported by the German Research Foundation DFG (grant MA 2621/4-1 to JM; grant CRC1181, project C04 to JM). The funders had no role in study design, data collection and analysis, decision to publish, or preparation of the manuscript.

\section{Copyright}

(C) The Author(s) 2021. 


\section{References}

1. M'Koma AE. Inflammatory bowel disease: an expanding global health problem. Clin Med Insights Gastroenterol. 2013;6:33-47.

2. GBD 2017 Inflammatory Bowel Disease Collaborators. The global, regional, and national burden of inflammatory bowel disease in 195 countries and territories, 1990-2017: a systematic analysis for the global burden of disease study 2017. Lancet Gastroenterol Hepatol. 2020;5:17-30.

3. Jairath V, Feagan BG. Global burden of inflammatory bowel disease. Lancet Gastroenterol Hepatol. 2020;5:2-3.

4. Sandborn WJ. State-of-the-art: immunosuppression and biologic therapy. Dig Dis. 2010;28:536-42.

5. Irvine EJ. Quality of life of patients with ulcerative colitis: past, present, and future. Inflamm Bowel Dis. 2008;14:554-65.

6. Clark M, Colombel JF, Feagan BC, Fedorak RN, Hanauer SB, Kamm MA, et al. American gastroenterological association consensus development conference on the use of biologics in the treatment of inflammatory bowel disease, June 21-23, 2006. Gastroenterology. 2007;133:312-39.

7. Rocchi A, Benchimol EI, Bernstein CN, Bitton A, Feagan B, Panaccione R, et al. Inflammatory bowel disease: a Canadian burden of illness review. Can J Gastroenterol. 2012;26:811-7.

8. Martinez-Medina M, Denizot J, Dreux N, Robin F, Billard E, Bonnet R, et al. Western diet induces dysbiosis with increased E coli in CEABAC10 mice, alters host barrier function favouring AIEC colonisation. Gut. 2014;63:116-24.

9. Baillie M. The morbid anatomy of some of the most important parts of the human body. Albany [N.Y.]: Printed by Barber \& Southwick. 1795.

10. Wilks S. Morbid appearances in the intestine of miss bankes. London Med Gaz. 1859;2:264.

11. Sairenji T, Collins KL, Evans DV. An update on inflammatory bowel disease. Prim Care. 2017;44:673-92.

12. Actis GC, Pellicano R, Fagoonee S, Ribaldone DG. History of inflammatory bowel diseases. J Clin Med. 2019;8.

13. Malekzadeh MM, Vahedi H, Gohari K, Mehdipour P, Sepanlou SG, Daryani NE, et al. Emerging epidemic of inflammatory bowel diseases in a middle income country: a nation-wide study from Iran. Arch Iran Med. 2016;19:2-15.

14. Both H, Torp-Pedersen K, Kreiner S, Hendriksen C, Binder V. Clinical appearance at diagnosis of ulcerative colitis and Crohn's disease in a regional patient group. Scand J Gastroenterol. 1983;18:987-91.

15. Kochhar R, Sriram PV, Sharma SC, Goel RC, Patel F. Natural history of late radiation proctosigmoiditis treated with topical sucralfate suspension. Dig Dis Sci. 1999;44:973-8.

16. Marshall JB, Butt JH. Proctitis: approach to diagnosis, causes and treatment. J Clin Gastroenterol. 1982;4:431-44.

17. Baumgart DC. The diagnosis and treatment of Crohn's disease and ulcerative colitis. Dtsch Arztebl Int. 2009;106:123-33.

18. Cuffari C, Present DH, Bayless TM, Lichtenstein GR. Optimizing therapy in patients with pancolitis. Inflamm Bowel Dis. 2005;11:937-46.

19. Veloso FT, Carvalho J, Magro F. Immune-related systemic manifestations of inflammatory bowel disease: a prospective study of 792 patients. J Clin Gastroenterol. 1996;23:29-34.

20. Abraham C, Cho JH. Inflammatory bowel disease. N Engl J Med. 2009;361:2066-78.

21. Brant SR. Update on the heritability of inflammatory bowel disease: the importance of twin studies. Inflamm Bowel Dis. 2011;17:1-5.

22. Cho JH, Brant SR. Recent insights into the genetics of inflammatory bowel disease. Gastroenterology. 2011;140:1704-12. 
23. Yamazaki K, McGovern D, Ragoussis J, Paolucci M, Butler H, Jewell D, et al. Single nucleotide polymorphisms in TNFSF15 confer susceptibility to Crohn's disease. Hum Mol Genet. 2005;14: 3499-506.

24. Klein RJ, Zeiss C, Chew EY, Tsai JY, Sackler RS, Haynes C, et al. Complement factor H polymorphism in age-related macular degeneration. Science. 2005;308:385-9.

25. McGovern DPB, Kugathasan S, Cho JH. Genetics of inflammatory bowel diseases. Gastroenterology. 2015;149:1163-76.e2.

26. Zhao M, Burisch J. Impact of genes and the environment on the pathogenesis and disease course of inflammatory bowel disease. Dig Dis Sci. 2019;64:1759-69.

27. Knox NC, Forbes JD, Van Domselaar G, Bernstein CN. The gut microbiome as a target for IBD treatment: are we there yet? Curr Treat Options Gastroenterol. 2019;17:115-26.

28. Huang $\mathrm{Q}, \mathrm{Li}$ X, Elkhooly $\mathrm{TA}$, Liu X, Zhang $\mathrm{R}$, Wu H, et al. The $\mathrm{Cu}$-containing $\mathrm{TiO}_{2}$ coatings with modulatory effects on macrophage polarization and bactericidal capacity prepared by micro-arc oxidation on titanium substrates. Colloids Surf B Biointerfaces. 2018;170:242-50.

29. Baier J, Gänsbauer M, Giessler C, Arnold H, Muske M, Schleicher U, et al. Arginase impedes the resolution of colitis by altering the microbiome and metabolome. J Clin Invest. 2020;130:5703-20.

30. Vilas-Boas W, Cerqueira BAV, Zanette AMD, Reis MG, Barral-Netto M, Goncalves MS. Arginase levels and their association with Th17-related cytokines, soluble adhesion molecules (sICAM-1 and sVCAM-1) and hemolysis markers among steady-state sickle cell anemia patients. Ann Hematol. 2010;89:877-82.

31. El Kasmi KC, Qualls JE, Pesce JT, Smith AM, Thompson RW, Henao-Tamayo M, et al. Toll-like receptorinduced arginase 1 in macrophages thwarts effective immunity against intracellular pathogens. Nat Immunol. 2008;9:1399-406.

32. Jostins L, Ripke S, Weersma RK, Duerr RH, McGovern DP, Hui KY, et al. Host-microbe interactions have shaped the genetic architecture of inflammatory bowel disease. Nature. 2012;491:119-24.

33. Liu JZ, van Sommeren S, Huang H, Ng SC, Alberts R, Takahashi A, et al. Association analyses identify 38 susceptibility loci for inflammatory bowel disease and highlight shared genetic risk across populations. Nat Genet. 2015;47:979-86.

34. Aristoteles LR, Righetti RF, Pinheiro NM, Franco RB, Starling CM, da Silva JC, et al. Modulation of the oscillatory mechanics of lung tissue and the oxidative stress response induced by arginase inhibition in a chronic allergic inflammation model. BMC Pulm Med. 2013;13:52.

35. Fritz JH. Arginine cools the inflamed gut. Infect Immun. 2013;81:3500-2.

36. Albaugh VL, Pinzon-Guzman C, Barbul A. Arginine-Dual roles as an onconutrient and immunonutrient. J Surg Oncol. 2017;115:273-80.

37. Abraham C, Cho JH. IL-23 and autoimmunity: new insights into the pathogenesis of inflammatory bowel disease. Annu Rev Med. 2009;60:97-110.

38. Lundberg JO, Weitzberg E, Gladwin MT. The nitrate-nitrite-nitric oxide pathway in physiology and therapeutics. Nat Rev Drug Discov. 2008;7:156-67.

39. Jenkinson CP, Grody WW, Cederbaum SD. Comparative properties of arginases. Comp Biochem Physiol B Biochem Mol Biol. 1996;114:107-32.

40. Gad MZ. Anti-aging effects of $L$-arginine. J Adv Res. 2010;1:169-77.

41. Endo M, Oyadomari S, Terasaki Y, Takeya M, Suga M, Mori M, et al. Induction of arginase I and II in bleomycin-induced fibrosis of mouse lung. Am J Physiol Lung Cell Mol Physiol. 2003;285:L313-21.

42. Wynn TA, Ramalingam TR. Mechanisms of fibrosis: therapeutic translation for fibrotic disease. Nat Med. 2012;18:1028-40.

43. Pegg AE. Toxicity of polyamines and their metabolic products. Chem Res Toxicol. 2013;26:1782-800. 
44. Kocna P, Fric P, Zavoral M, Pelech T. Arginase activity determination a marker of large bowel mucosa proliferation. Eur J Clin Chem Clin Biochem. 1996;34:619-23.

45. Pillai RB, Tolia V, Rabah R, Simpson PM, Vijesurier R, Lin CH. Increased colonic ornithine decarboxylase activity in inflammatory bowel disease in children. Dig Dis Sci. 1999;44:1565-70.

46. Horowitz S, Binion DG, Nelson VM, Kanaa Y, Javadi P, Lazarova Z, et al. Increased arginase activity and endothelial dysfunction in human inflammatory bowel disease. Am J Physiol Gastrointest Liver Physiol. 2007;292:G1323-36.

47. Akazawa Y, Kubo M, Zhang R, Matsumoto K, Yan F, Setiawan H, et al. Inhibition of arginase ameliorates experimental ulcerative colitis in mice. Free Radic Res. 2013;47:137-45.

48. Coburn LA, Horst SN, Allaman MM, Brown CT, Williams CS, Hodges ME, et al. $L$-arginine availability and metabolism is altered in ulcerative colitis. Inflamm Bowel Dis. 2016;22:1847-58.

49. Steppan J, Nyhan D, Berkowitz DE. Development of novel arginase inhibitors for therapy of endothelial dysfunction. Front Immunol. 2013;4:278.

50. Weisser SB, Kozicky LK, Brugger HK, Ngoh EN, Cheung B, Jen R, et al. Arginase activity in alternatively activated macrophages protects PI3Kp110delta deficient mice from dextran sodium sulfate induced intestinal inflammation. Eur J Immunol. 2014;44:3353-67.

51. Gobert AP, Cheng Y, Akhtar M, Mersey BD, Blumberg DR, Cross RK, et al. Protective role of arginase in a mouse model of colitis. J Immunol. 2004;173:2109-17.

52. Gobert AP, Daulouede S, Lepoivre M, Boucher JL, Bouteille B, Buguet A, et al. Arginine availability modulates local nitric oxide production and parasite killing in experimental trypanosomiasis. Infect Immun. 2000;68:4653-7.

53. Caldwell RB, Toque HA, Narayanan SP, Caldwell RW. Arginase: an old enzyme with new tricks. Trends Pharmacol Sci. 2015;36:395-405.

54. Heinsbroek SE, Gordon S. The role of macrophages in inflammatory bowel diseases. Expert Rev Mol Med. 2009;11:e14.

55. Cho DI, Kim MR, Jeong HY, Jeong HC, Jeong MH, Yoon SH, et al. Mesenchymal stem cells reciprocally regulate the M1/M2 balance in mouse bone marrow-derived macrophages. Exp Mol Med. 2014;46:e70.

56. Cassetta L, Cassol E, Poli G. Macrophage polarization in health and disease. SciWorld J. 2011;11:2391-402.

57. Leung G, Wang A, Fernando M, Phan VC, McKay DM. Bone marrow-derived alternatively activated macrophages reduce colitis without promoting fibrosis: participation of IL-10. Am J Physiol Gastrointest Liver Physiol. 2013;304:G781-92.

58. Martinez FO, Helming L, Gordon S. Alternative activation of macrophages: an immunologic functional perspective. Annu Rev Immunol. 2009;27:451-83.

59. Matsumoto M, Kibe R, Ooga T, Aiba Y, Kurihara S, Sawaki E, et al. Impact of intestinal microbiota on intestinal luminal metabolome. Sci Rep. 2012;2:233.

60. Manichanh C, Rigottier-Gois L, Bonnaud E, Gloux K, Pelletier E, Frangeul L, et al. Reduced diversity of faecal microbiota in Crohn's disease revealed by a metagenomic approach. Gut. 2006;55:205-11.

61. Takahashi K, Nishida A, Fujimoto T, Fujii M, Shioya M, Imaeda H, et al. Reduced abundance of butyrate-producing bacteria species in the fecal microbial community in Crohn's disease. Digestion. 2016;93:59-65.

62. Moustafa A, Li W, Anderson EL, Wong EHM, Dulai PS, Sandborn WJ, et al. Genetic risk, dysbiosis, and treatment stratification using host genome and gut microbiome in inflammatory bowel disease. Clin Transl Gastroenterol. 2018;9:e132.

63. Goodrich JK, Waters JL, Poole AC, Sutter JL, Koren O, Blekhman R, et al. Human genetics shape the gut microbiome. Cell. 2014;159:789-99. 
64. Guo P, Zhang K, Ma X, He P. Clostridium species as probiotics: potentials and challenges. J Anim Sci Biotechnol. 2020;11:24.

65. Elrod JW, Laroux FS, Houghton J, Carpenter A, Ando T, Jennings MH, et al. DSS-induced colitis is exacerbated in STAT-6 knockout mice. Inflamm Bowel Dis. 2005;11:883-9.

66. ChauhanSD, Seggara G,Vo PA, MacAllister RJ, Hobbs AJ, Ahluwalia A. Protection againstlipopolysaccharideinduced endothelial dysfunction in resistance and conduit vasculature of iNOS knockout mice. FASEB J. 2003;17:773-5.

67. Kasten J, Hu C, Bhargava R, Park H, Tai D, Byrne JA, et al. Lethal phenotype in conditional late-onset arginase 1 deficiency in the mouse. Mol Genet Metab. 2013;110:222-30.

68. Ballantyne LL, Sin YY, St Amand T, Si J, Goossens S, Haenebalcke L, et al. Strategies to rescue the consequences of inducible arginase-1 deficiency in mice. PLoS One. 2015;10:e0125967.

69. Rosenthal MD, Carrott PW, Patel J, Kiraly L, Martindale RG. Parenteral or enteral arginine supplementation safety and efficacy. J Nutr. 2016;146:2594S-600S.

70. Wilmore D. Enteral and parenteral arginine supplementation to improve medical outcomes in hospitalized patients. J Nutr. 2004;134:2863S-7S.

71. Wilson AM, Harada R, Nair N, Balasubramanian N, Cooke JP. $L$-arginine supplementation in peripheral arterial disease: no benefit and possible harm. Circulation. 2007;116:188-95.

72. Coburn LA, Gong X, Singh K, Asim M, Scull BP, Allaman MM, et al. L-arginine supplementation improves responses to injury and inflammation in dextran sulfate sodium colitis. PLoS One. 2012;7:e33546.

73. Singh K, Gobert AP, Coburn LA, Barry DP, Allaman M, Asim M, et al. Dietary arginine regulates severity of experimental colitis and affects the colonic microbiome. Front Cell Infect Microbiol. 2019;9:66. 